\title{
Mikro Denetleyici Sistemler ile Türk İşaret Dili Kelime Çevirici
}

\author{
Fatih Gökçe ${ }^{1 *}$, Hakan Kekül2

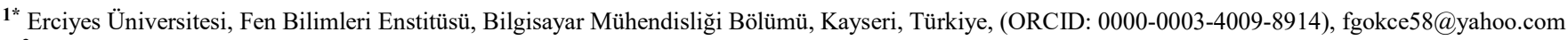 \\ ${ }^{2}$ Frrat Üniversitesi, Fen Bilimleri Enstitüsü, Bilgisayar Mühendisliği Bölümü, Elazı̆̆, Türkiye (ORCID: 0000-0001-6269-8713), hakankekul@gmail.com
}

(1st International Conference on Applied Engineering and Natural Sciences ICAENS 2021, November 1-3, 2021)

(DOI: 10.31590/ejosat.1012347)

\begin{abstract}
ATIF/REFERENCE: Gökçe, F. \& Kekül, H. (2021). Mikro Denetleyici Sistemler ile Türk İşaret Dili Kelime Çevirici. Avrupa Bilim ve Teknoloji Dergisi, (28), 972-977.

$\ddot{\mathbf{O z}}$

Bu çalışmanın amacı Türkçe dilinde kullanılan kelimelerin işaret dili karşılıklarını, oluşturulan model yardımıyla tespit etmektir. Bu sayede konuşma engelli bireyler ve toplumun geri kalanı arasındaki iletişimin kolaylaştırılması amaçlanmaktadır. Konuşma engelliler ile engelli olmayan bireyler arasında iletişim sağlamak her zaman zor olmuştur. Engelli ve engelli olmayan bireyler arasında iletişimi sağlamak için önerilen yöntem, mikro denetleyici (Arduino), görüntüleme birimi (LCD Panel) ile flex, ivme ve gyro sensörler kullanmaktadır. Kelimelerin modellenebilmesi için bir eldiven tasarlanmıştır. İşaret dili çevirici eldiven sayesinde engelli bireylerle engelli olmayan bireyler iletişim sağlayabileceklerdir. İşaret dili çeviriciyi eline takan engelli bir birey işaret dilindeki bir sözcüğü işaret ettiğinde eldiven üzerindeki her bir parmağa denk gelen beş flex, ivme ve gyro sensörlerinden gelen veriler mikro denetleyiciye aktarılmaktır. Mikro denetleyicide işaret dili çevirici eldivenden gelen bu verilere göre işaretin hangi ifadeyi kastettiğini tespit ederek görüntüleme biriminde yazı olarak göstermektedir. İşaret dili çevirici projesinde işaret dilindeki kelimeleri çevirirken Türk işaret dili kullanılmıştır. İşaret dilinde hareketi yapılan bir ifadenin ne anlama geldiğini görüntüleme biriminde göstermek için, örnek olarak seçilen işaret dili hareketlerinin işaret dili çevirici eldiven takılarak yapıldığında elde edilen beş flex sensör verisi, üç ivme verisi ve üç gyro verisi olmak üzere toplam onbir verinin değerleri tespit edilmiştir. Örnek seçilen her işaret dili hareketi için tespit edilen onbir veri kayıt edilmiştir. Mikro denetleyici üzerinde çalışan programda bu değerlere göre işaret dili hareketleri sınıflandırılmıştır.
\end{abstract}

Anahtar Kelimeler: Türk İşaret Dili, Flex Sensör, İvme Sensörü, Gyro Sensör, Mikro Denetleyici, Arduino.

\section{Turkish Sign Language Word Converter with Micro Controller Systems}

\begin{abstract}
The aim of this study is to determine the sign language equivalents of the words used in the Turkish language with the help of the model created. In this way, it is aimed to facilitate communication between speech-impaired individuals and the rest of the society. It has always been difficult to establish communication between speech impaired and non-disabled individuals. The proposed method to provide communication between disabled and non-disabled individuals uses microcontroller (Arduino), display unit (LCD Panel) and flex, acceleration and gyro sensors. A glove was designed to model words. Thanks to the sign language translator glove, disabled individuals and non-disabled individuals will be able to communicate. When a disabled person wearing a sign translator points to a word in sign language, the data from the five flex, acceleration and gyro sensors corresponding to each finger on the glove is transferred to the microcontroller. In the microcontroller, the sign language translator detects which expression the sign means according to this data coming from the glove and displays it as text in the display unit. In the sign language translator project, Turkish sign language was used while translating the words in the sign language. In order to show what an expression in sign language means in the display unit, the values of a total of eleven data, five flex sensor data, three acceleration data and three gyro data, obtained when the selected sign language movements are made by wearing sign language translator gloves, were determined. Eleven data were recorded for each selected sign language gesture. Sign language movements are classified according to these values in the program running on the microcontroller.
\end{abstract}

Keywords: Turkish Sign Language, Flex Sensor, Acceleration Sensor, Gyro Sensor, Micro Controller, Arduino.

* Sorumlu Yazar: fgokce58@yahoo.com 


\section{Giriş}

Engellik, insanların günlük yaşamsal aktivitelerini olumsuz yönde etkileyen zihinsel ve fiziksel problemlerdir. Engelli bireyler yaşadıkları sorunlar nedeni ile sosyal toplumdan uzaklaşabilmektedir. (Burcu, 2015)

Konuşamamak engel nedenlerinden sadece bir tanesidir. Konuşma engelli bireylerin yaşadıkları en büyük problem yaşadıkları toplumla iletişim kuramamalarıdır. Bunun temel nedeni işaret dilinin toplumun diğer bireyleri tarafından anlaşılamamasıdır. Bu sorun konuşma engelli bireylerin kamusal hizmetler dâhil pek çok alanda zorluk yaşamalarına neden olmaktadır. (Öztabak, 2017)

Sarkar vd. (2009) Bangladeş dilinde geliştirdikleri işaret dili çevirmen yazılımı ile işitme engelli bireylerin eğitimlerinde yaşadıkları iletişim problemlerine çözüm üretmeye çalışmışlardır. Ayrıca yöntemlerinin işitme engelli bireylerin yazılı ve işaret dilini öğrenmek için bir araç olarak kullanılabileceğini vurgulamaktadırlar.

$\mathrm{Ku}$, Chen ve King (2019) İşitme engelli bireylerin toplum içerisinde anlaşılmalarındaki güçlüğe çözüm olarak hayatın her noktasında yanımızda bulunan mobil cihazlar üzerinden bir çözüm önermektedir. Amerikan işaret dilindeki üç kelimeyi tahmin etmek için cep telefonlarında çalışan bir uygulama geliştirmişlerdir. Çalışmalarında \%80 başarı oranı yakaladıklarını vurgulamaktadırlar. Ayrıca önerdikleri yöntemim işitme engelli bireylerin toplumsal iletişiminde yardımcı olabileceğini belirtmektedirler.

El-Bendary vd. (2010) Arap alfabesinde bulunan harflerin işaret dili hareketlerinden çeviren ArSLAT adını verdikleri çalışmalarını sunmaktadır. Çalışmalarında görüntüler üzerinden harflerin tahminini gerçekleştirmektedirler. Sistemlerinin herhangi bir eldiven veya donanıma ihtiyaç duymadığını özellikle vurgulamaktadırlar. Çalışmalarının sonucunda 30 Arap harfini \%91,3 doğruluk değeri ile tahmin ettiklerini belirtmektedirler.

Abhishek, Qubeley ve Ho (2016) çalışmalarında İngiliz alfabesindeki 26 harf ve 0-9 arasındaki rakamları işaret dilinden tahmin eden yöntem önermektedirler. Yöntemleri bir eldiven düzeneği üzerinden karakterleri tanımaya çalışmaktadır. Önerilen yöntemin \%92 oranında başarı gösterdiğini belirtmektedirler. Yöntemlerinin muadilleri ile karşılaştırılabilir olduğunu söylemişlerdir.

Yalçın, Ilgaz, Özkul ve Yıldız (2018) çalışmalarında Türkçe alfabedeki harfleri tahmin etmek için bir yöntem önermektedirler. Yöntemleri, oluşturdukları bir eldiven üzerinden elde ettikleri verileri mikro denetleyici üzerinden sınıflandırmak üzere modellenmiştir. İşaret dilinde bulunan harfleri tanımlamak için tek bir eldiven kullandıkları için sadece tek elle oluşturulabilen harfleri sınıflandırmışlardır. Sınıflandırdıkları harf sayısı on beştir.

İşitme kaybı yaşayan bireylerin iletişim araçları işaret dilidir. Dünya genelinde yaklaşı 360 milyon insanın bu problemi

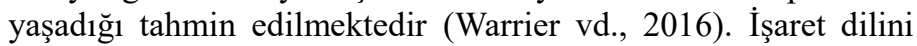
toplumun geneline öğretmek şuan için mümkün görünmemektedir.

Ancak gelişen teknolojinin bu soruna çözüm üretebileceği düşünülmektedir (Starner, Weaver ve Pentland, 1998). Bu sorunun çözümünde genellikle görüntü işleme tabanlı çözümlere odaklanılmıştır (Yalçın vd., 2018). Günümüzde hızla gelişen giyilebilir teknolojilerin bu problem özelinde daha başarılı ve kullanılabilir sonuçlar verebileceğini değerlendiriyoruz.

Toplumda engelli bireylerin kullanacağı ve hayatını kolaylaştıracağı sistemlerin eksikliği hissedilmektedir. Konuşma engelliler ile engelli olmayan bireyler arasında iletişim sağlamak her zaman zor olmuştur. $\mathrm{Bu}$ durum toplumda büyük bir sorun olarak karşımıza çıkmaktadır. Yukarıdaki literatür incelendiğinde dünyada bilişim sistemlerinin bu sorunun çözümünde aktif olarak kullanılmaya çalışıldığı açıkça görülmektedir. Dahası pek çok dil üzerinde farklı çalışmalar yapıldığı anlaşılmaktadır. Türk işaret dili üzerine de çalışmalar yapılmaktadır. Ancak literatürden anlaşıldığı üzere çalışmaların geneli harf ve rakam gibi karakterlerin tespit edilmesi üzerinedir. Bu çalışma, karakterleri değil doğrudan iletişimde kullanılan kelimeleri sınıflandırmayı amaçlamıştır. Bunun için günlük kullanımda sıklıkla kullanılan kelimelerin tanımlanması yoluna gidilmiştir.

\section{Materyal ve Metot}

Giyilebilir teknolojiler farklı kullanım alanlarının yanında engelli bireylerin ihtiyaçlarını gidermek içinde kullanılmaktadır. Giyilebilir teknolojilerin bir uygulaması da konuşma engelli bireyler için geliştirilen cihazlardır. İşitme engeli olmayan insanların işitme engelli kişiler tarafından kullanılan işaret dilini kolayca anlayabilmeleri için bir iletişim yaklaşımı geliştirmek amacıyla işaret dili çevirici yöntemi önerilmektedir. Bu sebeple konuşma engelli bireyler ile diğer bireyler arasında iletişimi sağlamak için işaret dili çevirici eldiven geliştirilmiştir. Böylece işaret dili tercümanı ihtiyacı ortadan kalkmış olur.

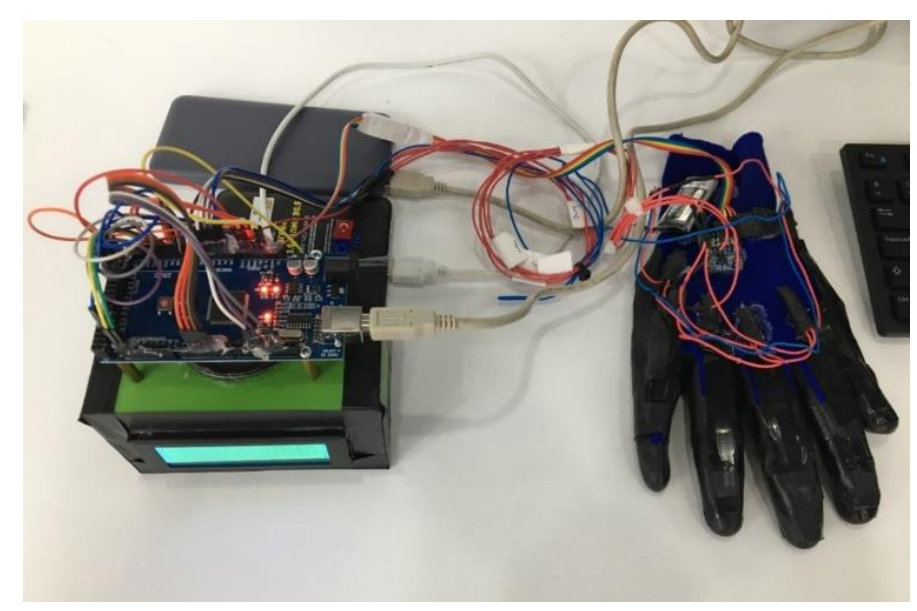

Şekil 1 İşaret dili çevirici sistemi

İşaret dili çevirici sistemi, işaret dili hareketlerinin anlamını LCD panelde gösteren bir el hareketi tanıma sistemi içerir. Örneğin, işitme engelli kişi işaret dili çevirici eldivenini takıp 'Merhaba' hareketi yaptığında, metin çıktısı olarak LCD panelde 'Merhaba' yazar. Şekil 1'de önerilen yöntemin tasarımı görünmektedir.

Projede Türk işaret dili kullanılmıştır. Örnek olarak seçilen işaret dili hareketlerinin her birinin yapılması sırasında 5 flex sensör, 3 ivmeölçer ve 3 jiroskop değerlerinin verileri seri port ekranı kullanılarak elde edilmiş ve kaydedilmiştir. Daha sonra mikro denetleyici aracılığıyla bu hareketler için toplamda 11 veriye göre program yazılmıştır. Projenin çalışma sisteminde, bir hareket için elde edilen veriler oluştuğunda o hareketin karşılığ 
olan kelime LCD ekranda yazdırılmaktadır. İşaret dili çevirici eldiveni eline takan konuşma engelli bir birey, iletişim kurmak istediği bireye anlatmak istediği bir hareketi yaptığında o işaret dili hareketinin karşılığı LCD panelde yazdırılmaktadır.

\subsection{Kullanılan Malzemeler}

Önerilen yöntemin prototip geliştirme aşamasında kullanılan sensörlerin ve malzemelerin listesi tablo 1'de açıklanmıştır. İşaret dili çeviri eldiven tasarımında beş adet flex sensör parmakların hareket şekillerini belirlemek için kullanılmıştır. MPU 6050 Sensör içerisinde ivme ve jiroskop sensörleri barındırmaktadır. İvmeölçer ile hareketin ivmesi takip edilmektedir. Jiroskop ise elin konumsal eğim bilgisinin alınmasını sağlamaktadır. Elde edilen veriler arduino mikro denetleyici üzerinden işlenmektedir. Ayrıca sonuçların görüntülenebilmesi için LCD ekran kullanılmaktadır.

Tablo 1. Kullanılan Malzeme Listesi

\begin{tabular}{l|c}
\hline Malzeme Adı & Âdeti \\
\hline Arduino Mega & 1 \\
\hline Flex Sensörler & 5 \\
\hline MPU6050 Sensör & 1 \\
\hline 20x4 LCD Ekran & 1 \\
\hline Jumper Kablolar & İhtiyaç kadar \\
\hline Eldiven & 1 \\
\hline 3D baskı kutu & 1 \\
\hline Potansiyometre & 1 \\
\hline Powerbank & 2 \\
\hline
\end{tabular}

\subsection{Sistem Tasarımı}

Önerilen yöntem prototip olarak geliştirilmeden önce bilgisayarlı tasarımı gerçekleştirilmiştir. Bu amaçla Proteus devre şeması çizim programı kullanılarak modelimizin şeması çizilmiştir. Çizim işleminden sonra ilk ön testleri bu çizim üzerinden gerçekleştirilmiştir. Şekil 2'de işaret dili çeviricinin devre şeması görünmektedir.

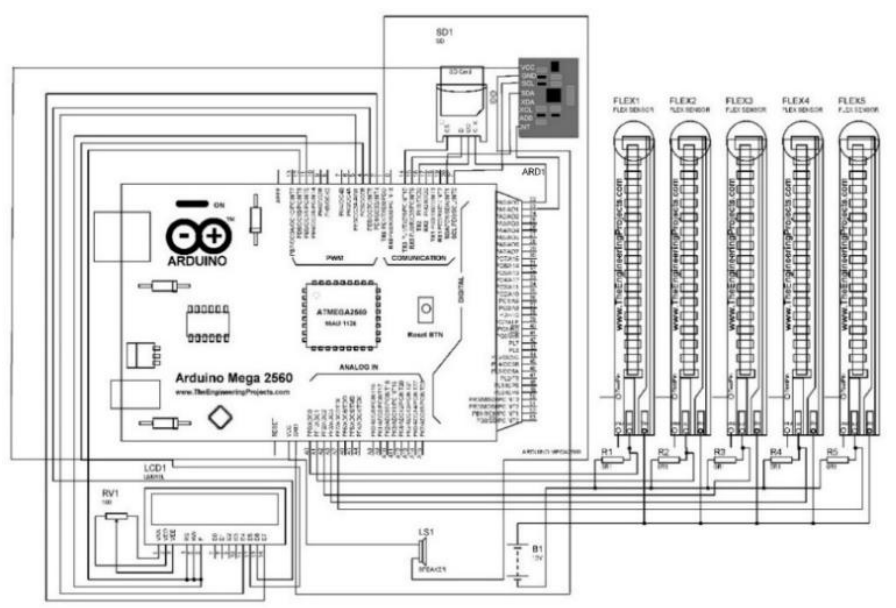

Şekil 2 İşaret dili çevirici devre şeması

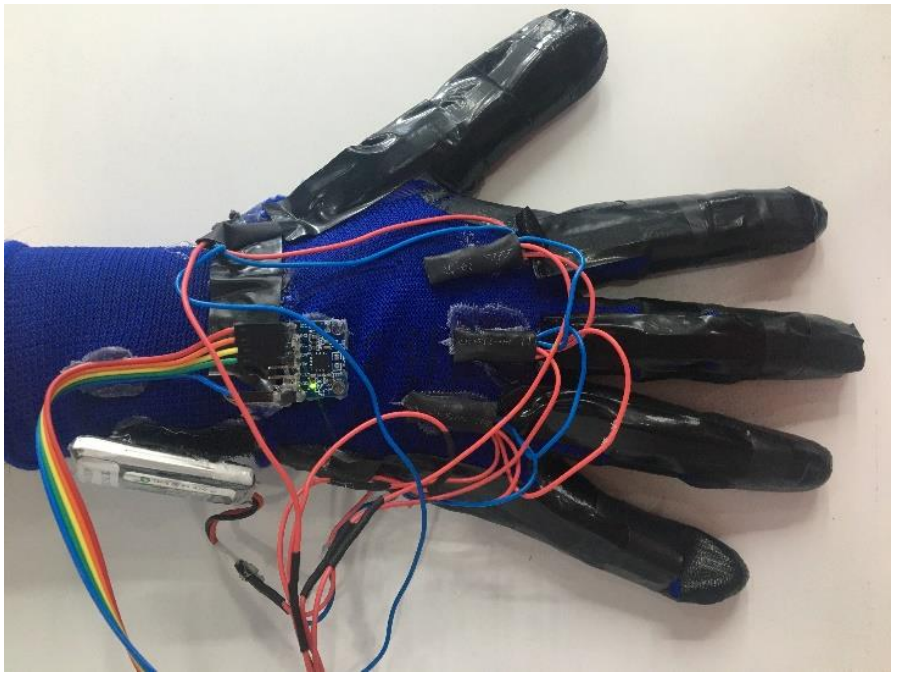

Şekil 3 Eldivenin bağlantıları

Önerilen yöntemin prototipinin oluşturulması aşamasında, ilk olarak eldivenin parmaklarının üzerine flex sensörler tutturulmuştur. Daha sonra devre şemasına göre Şekil 3'de görüldüğü gibi flex sensörler ile MPU 6050 bağlantıları gerçekleştirilmiştir. Daha sonra yine devre şemasına göre eldivenin Arduino Mega bağlantıları yapılmıştır. Son olarak LCD ekran ile Arduino Mega bağlantıları ve güç bağlantıları yapılmıştır. Şekil 3'de eldiven bağlantıları ayrıntıları ile görülmektedir.

Projenin örnek olarak seçilen işaret dili hareketlerinin verilerinin tespiti için her bir işaret dili hareketi 5 flex sensör değeri, 3 ivme-ölçer değeri ve 3 jiroskop değeri, mikro denetleyiciye seri port ekranı açılarak, işaret dili hareketi gerçekleştirildiği süre boyunca kaydedilmiştir. Bu işlem örnek olarak seçilen her işaret dili hareketi için yapılarak değerler ayrı ayrı kaydedilmiştir. Bu kaydedilen 11 veri aşağıdaki Şekil 4'de görülmektedir.

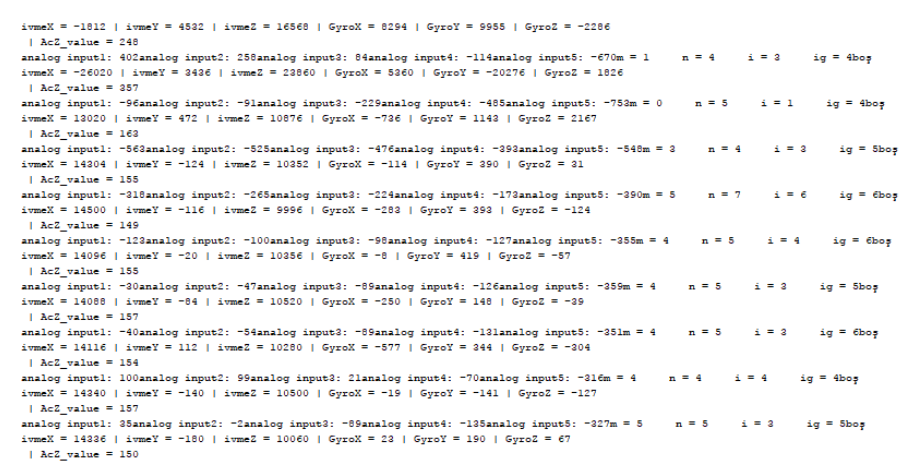

\section{Şekil 4 Kayıt edilen verilerin seri port ekranındaki görünümü}

Projenin mikro denetleyici üzerinde kodlaması yapılırken, ișaret dili hareketleri için elde edilen verilerin tam o değerde her zaman olamayacağı düşünülerek kodlamada şart yapısında sabit değil de okunan değerler arasında olması gerektiği değerlendirilmiş ve buna göre programın algoritması gerçekleştirilmiştir. Şekil 5 ve 6'da geliştirilen programın bazı kısımları görülmektedir. 
sensorl $=$ analogRead $(\mathrm{A} 0)$;

Serial.print ("analog input1: ");

Serial.print (sensor1, DEC);

sensor2 = analogRead $(\mathrm{A} 1)$;

Serial.print ("analog input2: ");

Serial.print (sensor2, DEC) ;

sensor $3=$ analogRead $(A 2)$;

Serial.print ("analog input3: ");

Serial.print (sensor3, DEC);

sensor $4=\operatorname{analogRead}(\mathrm{A} 3)$;

Serial.print ("analog input4: ");

Serial.print (sensor4, DEC) ;

sensor5= analogRead $(A 4)$;

Serial.print ("analog input5: ");

Serial.print (sensor5, DEC);

Şekil 5 Sensörlerden veri okuma kodları

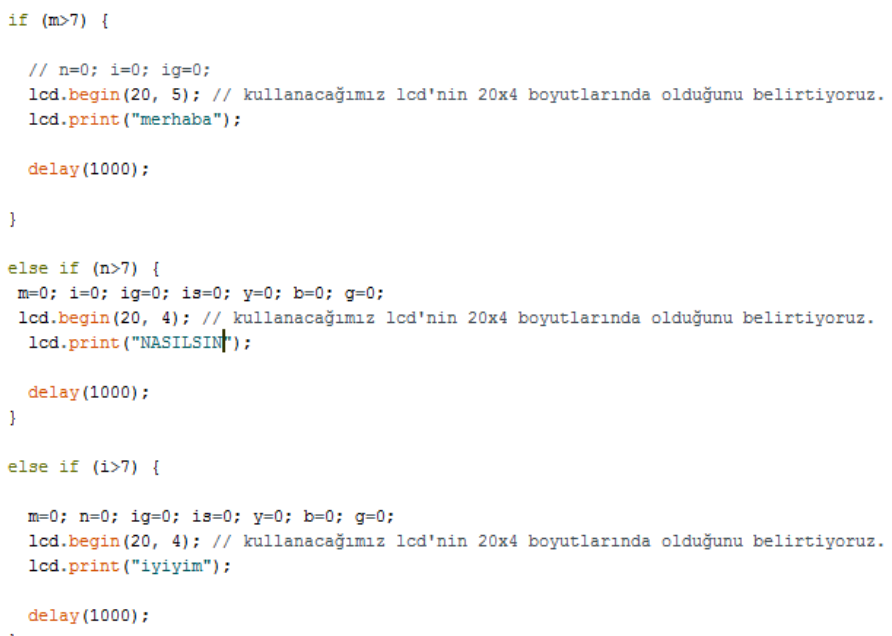

Şekil 6 İşaret dilindeki kelimelerin LCD ekrana yazdırılması

\section{Araştırma Sonuçları ve Tartışma}

\subsection{Bulgular}

Önerilen yöntem tamamlandıktan sonra test işlemleri gerçekleştirilmiştir. Test aşaması sırasında örnek olarak seçilen işaret dili hareketlerinden istikrarlı çalışmayan hareketlerin verileri seri port kullanılarak yeniden tespit edilmiş kodlar buna göre güncellenmiştir. Sonuç olarak örnek olarak seçilen işaret dili hareketleri, tasarlanan işaret dili çevirici sistemi sayesinde başarı ile sınıflandırılmış ve LCD ekrana yazdırılmıştır. Bu sayede konuşma engelli bir birey bu eldiveni takarak etrafındaki diğer bireylerle rahatlıkla iletişim kurabilmektedir.

Önerilen yöntem ile günlük hayatta sıklıkla kullanılan on farklı kelime başarı ile sınıflandırılmıştır. Aynı yöntemi kullanarak diğer kelimelerinde başarı ile sınıflandırılabileceği kanıtlanmıştır. Şekil 7,8,9' da bazı kelimelerin sınıflandırma sonuçları gösterilmiştir.

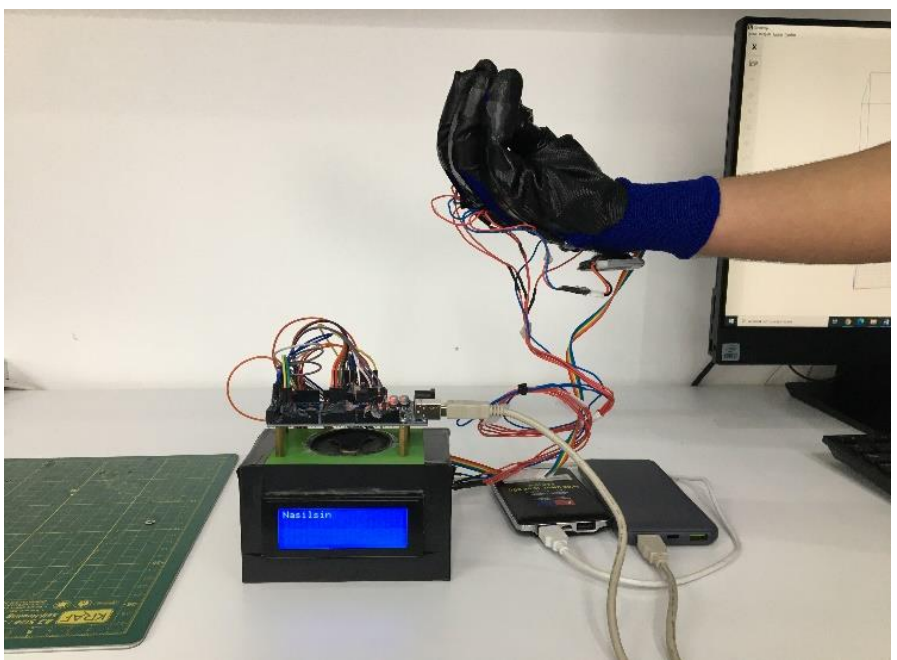

Şekil 7 "Nasılsın” kelimesinin işaret dilindeki karşılığ

Sinıflandırılan kelimelerden "Ben, İyiyim, Merhaba, Nasılsın ve Sen" sözcüklerinin işaret hareketlerinin, işaret dili çevirici eldiven ile yapılması sonucu ile elde edilen sensör verilerinin grafiği şekil 10,11 ve 12 'de görülmektedir. Şekil 10 flex sensörlerden elde edilen sonuçları göstermektedir. Oluşan şekil flex sensörlerin kelimeler için benzer değerler ürettiğini göstermektedir. İvme sensörünün verileri şekil 11 'de görülmektedir. $\mathrm{Bu}$ veriler ivme sensörünün kelimeler için ayırt edici sonuçlar üretebildiğini göstermektedir. Şekil 12'de jiroskop sensörü verileri, bazı kelimeler için benzer sonuçlar üretirken bazı kelimeler için çok farklı değerler üretebildiği açıça görülmektedir.

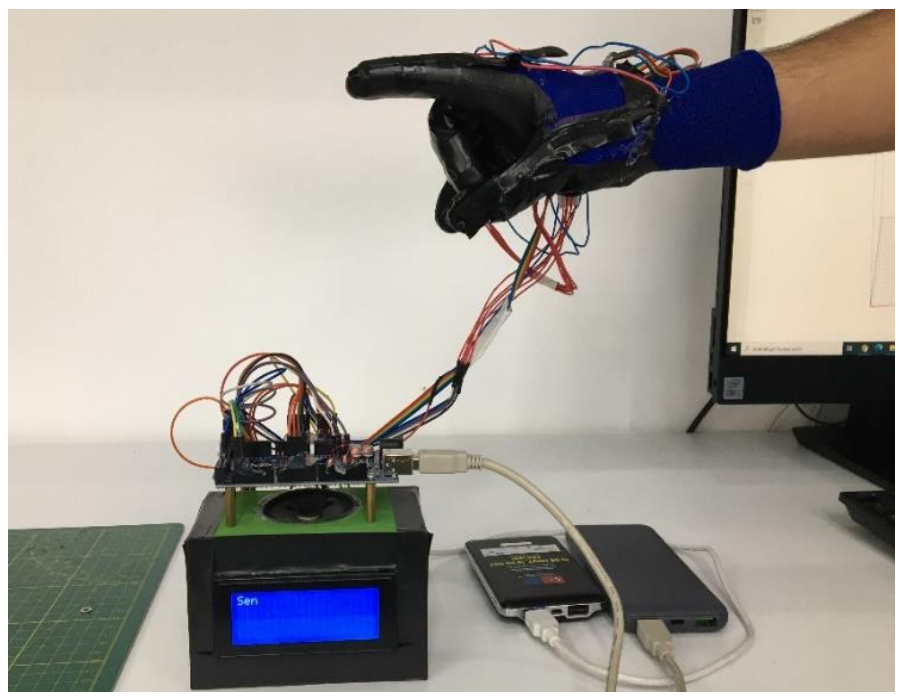

Şekil 8 “Sen” kelimesinin işaret dilindeki karşılığı 


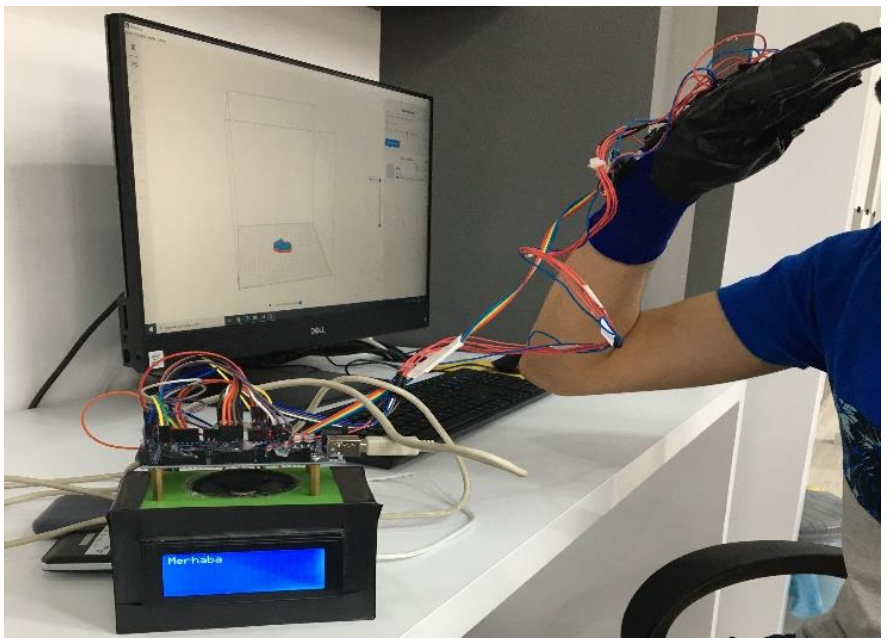

Şekil 9 "Merhaba” kelimesinin işaret dilindeki karşılığ

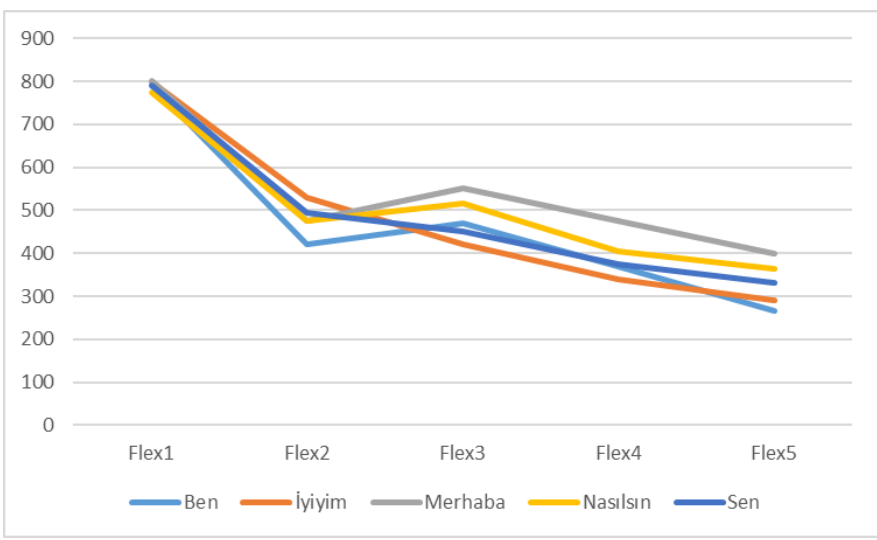

Şekil 10 Flex sensörlerin ortalama verileri

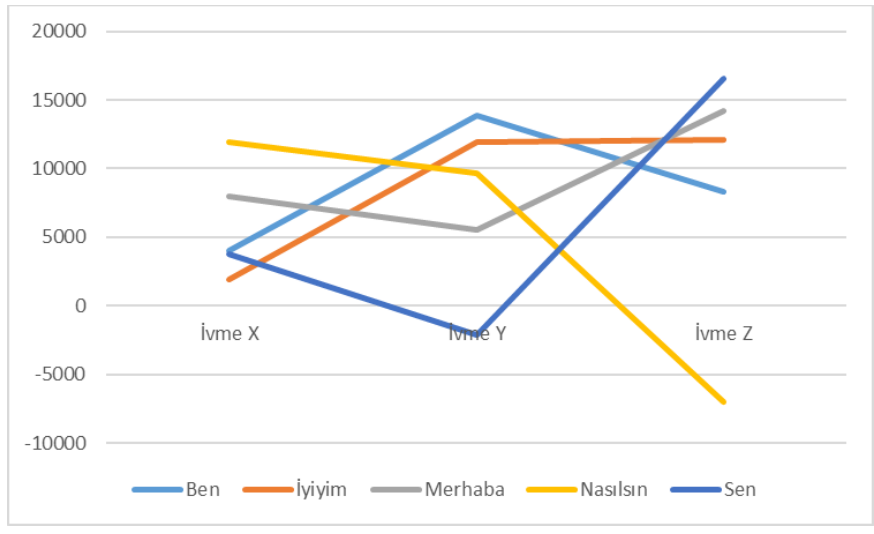

Şekil 11 İvme sensörlerin ortalama verileri

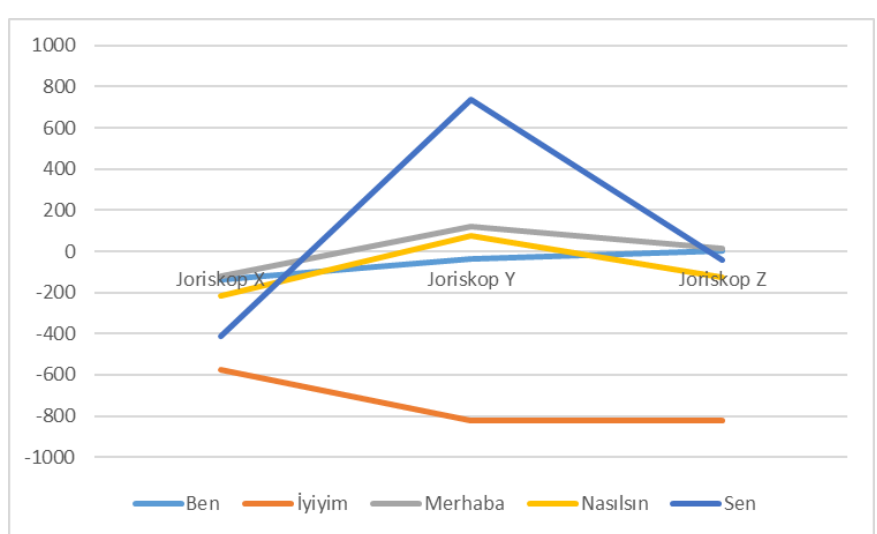

Şekil 12 Jiroskop sensörlerin ortalama verileri

\subsection{Tartışma}

Elde edilen verilerin sağlıklı değerlendirilmesi açısından sınıflandırma aşamasında kullanılan sensör verileri bir önceki bölümde açıkça verilmiştir. Bu verilerden anlaşılacağı üzere tek bir sensör verisi sınıflandırma için tek başına yeterli değildir. Sensörler içerisinde en fazla ayırt edici özellik içeren veriler ivme sensöründen elde edilmiştir. Özellikle flex sensörler parmak hareketlerini okuduklarından birçok kelime için bazıları sürekli benzer aralıklarda veriler üretmektedir. Bu nedenle tek başına en az ayırt edici özellikli veriyi sağlamaktadır. Diğer taraftan jiroskop sensörü bazı kelimelerde çok yakın ortalama değerler üretsede bazı kelimlerin verilerinde bağımsız sonuçlar üretmektedir. Özellikle aykırı ve nadir kelimelerin sınıflandırılmasında önemli bir fayda sağlayabilir.

Literatürde bulunan çalışmalarda maliyetli Kinect sensörler ile görüntü işleme kullanılarak işaret dili çevirici çalışmaları mevcuttur. Bu çalışmaların maliyetleri yüksektir. Ayrıca bazı çalışmalarda ise ücretli grafiksel programlama dilleri kullanılarak görüntülerden işaret dilinin tanınması gerçekleştirildiği görülmektedir (Phing vd., 2019). Farklı bir çalışmada ise Hint işaret dili hareketlerinin görüntülerinin çekilip matlab programında ayrıştırılması yöntemi ile işaret dili hareketleri sınıflandırılmıştır (Loke vd., 2017). Bu çalışmanın ise eş zamanlı çalışamaması dezavantajıdır.

Literatürde Türk işaret dili ile kelime sınıflandırma yapılan işaret dili çevirici bir sistem tespit edilememiştir. İşaret dili çevirici projesi Türk işaret dilini kullanması açısından özgündür. İşaret dili çevirici projesinde diğer çalışmalardan farklı olarak flex sensör ve MPU6050 gibi maliyeti uygun devre elamanları ile işaret dili hareketleri sınıflandırılmıştır. İşaret dili çevirici projesinin mikro denetleyici kodları özgün olarak yazılmıştır.

\section{Sonuç}

Elde edilen veriler sistemin geliştirilebilir olması açısından umut vericidir. İşaret dilinde harflerin ve rakamların yerine doğrudan kelimelerin tespit edilmesi iletişimin sağlanabilmesi açısından daha doğru bir yaklaşımdır. Ayrıca kelimelerin sınıflandırılmasında tek bir sensörden elde edilen verilerin ayırt edici olmadığ 1 açıktır. $\mathrm{Bu}$ nedenle farklı sensörlerin tüm kelimelerin sinıflandırılmasında birlikte kullanımı zorunlu görünmektedir. Yapılan deneysel çalışmalar işaret dilinin makineler tarafından anlaşılabilmesi açısından umut vericidir.

Prototip olarak tasarlanan ve kodlanan işaret dili çevirici sisteminin tam manada uygulamaya geçirilebilmesi için tüm Türk işaret dili sözcügüundeki kelimelerin verilerinin tespit edilip yazılıma uyarlanması gerekmektedir. Daha kararlı ve uygulanabilir bir sistem olabilmesi açısından eldiven ile yapılan bağlantıların kablosuz olmasının daha kullanışlı olacağı düşünülmektedir. Kablosuz bir eldiven tasarımı gerçekleştirilebilirse ticari olarak kullanımı daha uygun olur. Cümlelerin oluşması için ise, yazılan bir bilgisayar uygulaması ile haberleştirilmesi sağlanabilir. Bilgisayar programında başlat komutu verildiğinde her yapılan işarete göre çevrilen kelime bir dosyaya kaydedilip sonraki kelime ise dosyanın arkasına eklenerek cümleler oluşturulabilir. Yâda cümlelerin çevrilebilmesi için "Raspberry Pi" gibi dosya kaydetme ortamı olan mikrobilgisayarlar kullanılabilir. Bu yöntemle işaret dilinde yapılan cümlelerin yazıya çevrilmesi sağlanmış olur. Önerilen yöntemin uygulamasında flex sensörlerin hassas çalışamamasından kaynaklı riskler ortaya çıkabilir. $\mathrm{Bu}$ 
problemlere önlem almak için "Myo Armband - EMG sensör" gibi daha hassas çalışabilen sensörler tercih edilebilir.

\section{Kaynakça}

Abhishek, Kalpattu S., Lee Chun Fai Qubeley, and Derek Ho. "Glove-based hand gesture recognition sign language translator using capacitive touch sensor." 2016 IEEE International Conference on Electron Devices and SolidState Circuits (EDSSC). IEEE, 2016.

Burcu, E. (2015). Türkiye'de Yeni Bir Alan:'Engellilik Sosyolojisi've Gelişimi. Journal of Sociological Studies/Sosyoloji Konferanslari, (52).

El-Bendary, Nashwa, et al. "Arslat: Arabic sign language alphabets translator." 2010 international conference on computer information systems and industrial management applications (CISIM). IEEE, 2010.

$\mathrm{Ku}$, Yun-Jung, Min-Jen Chen, and Chung-Ta King. "A Virtual Sign Language Translator on Smartphones." 2019 Seventh International Symposium on Computing and Networking Workshops (CANDARW). IEEE, 2019.

Loke, Pranali, et al. "Indian sign language converter system using an android app." 2017 International conference of Electronics, Communication and Aerospace Technology (ICECA). Vol. 2. IEEE, 2017.

Öztabak, M. Ü. (2017). Engelli Bireylerin Yaşamdan Beklentilerinin İncelenmesi. FSM İlmî Araştırmalar İnsan ve Toplum Bilimleri Dergisi, (9), 355-355.

Phing, T. C., Ambar, R., Baharum, A., Poad, H. M., \& Abd Wahab, M. H. (2019). Wireless Wearable for Sign Language Translator Device using Intel UP Squared (UP 2) Board. In Computational Science and Technology (pp. 533-543). Springer, Singapore.

Phing, Tan Ching, et al. "Wireless Wearable for Sign Language Translator Device with Android-Based App." Intelligent and Interactive Computing. Springer, Singapore, 2019. 411-422.

Sarkar, B., Datta, K., Datta, C. D., Sarkar, D., Dutta, S. J., Roy, I. D., ... \& Paul, A. (2009, December). A translator for bangla text to sign language. In 2009 Annual IEEE India Conference (pp. 1-4). IEEE.

Starner, Thad, Joshua Weaver, and Alex Pentland. "Real-time american sign language recognition using desk and wearable computer based video." IEEE Transactions on pattern analysis and machine intelligence 20.12 (1998): 1371-1375.

Warrier, K. S., Sahu, J. K., Halder, H., Koradiya, R., \& Karthik Raj, V. (2016). Software based sign language converter. International Conference on Communication and Signal Processing, ICCSP 2016, 1777-1780. https://doi.org/10.1109/ICCSP.2016.7754472

Yalçin, M., Ilgaz, S., Özkul, G., \& Yildiz, Ş. K. (2018, May). Turkish sign language alphabet translator. In 2018 26th Signal Processing and Communications Applications Conference (SIU) (pp. 1-4). IEEE. 